\title{
eJRIEPS
}

Ejournal de la recherche sur l'intervention en éducation physique et sport

$18 \mid 2009$

Varia

\section{Actualités des livres}

André Terrisse, \& Marie-France Carnus (2009). La didactique clinique de l'éducation physique et sportive (EPS). Quels enjeux de savoirs?

\section{(2) OpenEdition}

1 Journals

Édition électronique

URL : http://journals.openedition.org/ejrieps/5521

DOI : 10.4000/ejrieps.5521

ISSN : 2105-0821

Éditeur

ELLIADD

Référence électronique

«Actualités des livres », eJRIEPS [En ligne], 18| 2009, mis en ligne le 01 juillet 2009, consulté le 18 mars 2021. URL : http://journals.openedition.org/ejrieps/5521 ; DOI : https://doi.org/10.4000/ejrieps. 5521

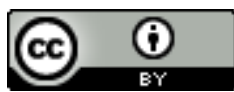

La revue eJRIEPS est mise à disposition selon les termes de la Creative Commons Attribution 4.0 International License. 
André Terrisse, \& Marie-France Carnus (2009). La didactique clinique de l'éducation physique et sportive (EPS). Quels enjeux de savoirs ? Bruxelles ; de Boeck Université.

Cet ouvrage est original, dans la mesure où il traite à la fois de questions générales, qui sont toujours d'actualité, comme le choix et la modalité de traitement des savoirs, en fonction du contexte et de la nature de la classe, tout y en incluant la part personnelle que prend l'enseignant dans ses décisions de choix et de traitement.

Si le terme de clinique est accolé à celui de didactique, c'est pour montrer combien la question des savoirs délivrés en classe est très dépendante, certes des Instructions Officielles, qui fixent les exigences institutionnelles, mais aussi et surtout du rapport qu'entretiennent les enseignants à ces savoirs.

En EPS, les enseignants se servent, dans l'institution scolaire, de connaissances extraites du champ sportif ou de loisir. Ils mènent des cycles de basket ball, d'endurance ou de natation, activités largement répandues dans le champ social.

Ce qui est interrogé dans cet ouvrage, c'est l'effet de ce rapport sur le traitement de ces APSA (Activités Physiques, Sportives et Artistiques). Un enseignant peut « aimer » ou « détester » la natation, mais il ne peut pas ne pas l'enseigner. Ce que cet ouvrage tente de décrire et d'expliquer, c'est justement en quoi ce rapport a un effet sur l'enseignement de cette activité.

Comme l'ont indiqué des chercheurs dans d'autres disciplines, cette question est pertinente pour un enseignant d'histoire qui enseigne aussi la géographie ou pour un enseignant de physique qui enseigne aussi la chimie !

D'où la question récurrente : en quoi le rapport personnel au savoir de l'enseignant détermine $t$ il son activité professionnelle? 